\title{
Como se dá a tomada de decisão das mulheres no cenário político em Sant'ana do Livramento.
}

How it is given the decision-making of women in the political scenario in Sant'ana of the Livramento

\author{
Rosemeri da S. Madrid1 \\ Sebastião Ailton Cequeira-Adão2
}

\section{RESUMO}

Este trabalho se propõe a entender como se dá na tomada de decisão das mulheres que ocupam espaço na Câmara Municipal de Sant'Ana do Livramento e no Gabinete de Vice-Prefeita da mesma cidade, considerando a necessidade de entender elas decidem a partir da sua representatividade política.

PALAVRAS-CHAVE: Mulher. Representatividade. Política. Tomada de Decisão.

\section{ABSTRACT}

This paper intends to understand how it occurs in the decision-making of the women who occupy space in the Sant'Ana do Livramento City Hall and in the Vice Mayor's Office of the same city, considering the need to understand them decide from their representativeness politics.

KEYWORDS: Woman. Representativity. Politics. Decision Making.

$$
* * *
$$

\section{Introdução}

As mulheres são, estatisticamente, maioria na sociedade totalizando $53 \%$ da população brasileira, segundo dados do Instituto Brasileiro de Geografia e Estatística (IBGE). Sua participação tem se ampliado cada vez mais nos espaços. Esta maioria, no entanto, não é refletida nos espaços de poder político, como nos ambientes legislativos e executivos, onde a representatividade social e as tomadas de decisão se dão por homens em maior número.

\footnotetext{
${ }^{1}$ Mestranda Programa de Pós-Graduação em Administração Universidade Federal do Pampa.

2 Professor Doutor da Universidade Federal do Pampa.
} 
Em Sant'Ana do Livramento, no Rio Grande do Sul, município de médio porte, localizado na fronteira Brasil-Uruguai, com uma população de 82 mil pessoas, não é diferente. A Câmara Municipal local possui dezessete legisladores e destes, apenas duas são mulheres ao passo que o Executivo da cidade tem à frente um prefeito, que foi eleito com uma mulher como viceprefeita, dando continuidade a uma tradição local de eleger homens para chefia da administração municipal.

Neste mesmo município, a maioria da população é composta por mulheres, segundo o último censo, 43.088 compunham a população local, enquanto que os homens eram 39.376 (IBGE) o que significa que 52,25\% da população é feminina enquanto a representatividade das mulheres na Câmara é de $11,7 \%$, temos então uma quase ausência de representatividade de gênero no legislativo.

Como cabe à Câmara a tomada de decisão quanto aos projetos, orçamentos e aprovação de políticas públicas no âmbito do município, este artigo busca inferir a percepção das legisladoras e da vice-prefeita quanto ao processo de tomada de decisão na arena política e a percepção das mesmas quanto à pouca representatividade feminina nos espaços de poder.

O Tribunal Superior Eleitoral (TSE) traz que as mulheres compõem a maior parte do eleitorado brasileiro, mas ainda estão longe de conseguir se eleger na mesma proporção dos homens. Segundo dados do Cadastro Eleitoral, são mais de 77 milhões de eleitoras em todo o Brasil, o que representa $52,5 \%$ do total de 147,5 milhões de eleitores. Desse número, apenas $9.204(31,6 \%)$ mulheres concorreram a um cargo eletivo nas Eleições Gerais de 2018. Destas, 290 foram eleitas, um aumento de 52,6\% em relação a 2014.

Apesar da desproporção, houve um avanço rumo à igualdade de gênero, com base no Cadastro Eleitoral, em 2014, foram escolhidas 190 mulheres para assumir os cargos em disputa, o que equivalia a $11,10 \%$ do total de 1.711 candidatos eleitos. Já no último pleito, as 290 eleitas correspondiam a 16,20\% do universo de 1.790 escolhidos, um crescimento de 5,10\% com relação à eleição anterior, conforme dados do TSE. 
Para a Câmara dos Deputados, em 2018, foram eleitas 77 parlamentares, um aumento de 51\% em relação ao último pleito, quando foram escolhidas 51 mulheres para a casa. Já nas assembleias legislativas, foram eleitas 161 representantes, um crescimento de 41,2\% em relação a 2014, quando foram escolhidas 114 mulheres para o cargo de deputada estadual.

Mesmo com este avanço na representatividade feminina nos espaços de poder político, muito ainda deve ser feito. Este artigo ajusta o foco na tomada de decisão das mulheres que ocupam espaço na Câmara Municipal de Sant'Ana do Livramento e no Gabinete de Vice-Prefeita da mesma cidade, considerando a necessidade de entender como estas mulheres decidem a partir da sua representatividade.

\section{Mulheres na politica}

Por sucessivas décadas ao longo da história, o papel da mulher foi resumido as tarefas da casa, da criação dos filhos e aos cuidados com o marido. Submissa, sem voz e invisibilizadas, cabia ao homem o protagonismo, a tomada de decisão, a provedoria, situação que no Brasil só começou a mudar em meados do século XIX, quando surgiram os primeiros relatos de mulheres que começaram a buscar seu espaço na sociedade.

Foi nesse período também que as muitas mulheres foram às ruas em busca de direitos, como por exemplo, o do voto, surgindo no Brasil o Partido Republicano Feminino, inserindo na história Leonilda Daltro, sua fundadora. Mesmo com este avanço, o período foi marcado por muitas dificuldades politicas para mulheres, como bem resume Bellozo (2008)

A igualdade alcançada com o sufrágio universal, no caso do Brasil, em 1952, que a torna elegível e eleitora, não significou profundas alterações das condições da mulher, pois a realidade que podia ser entendida como motivadora da desigualdade entre homens e mulheres não foi alterada com sua inserção no processo político, como não se alterou posteriorente, de modo que se pode pensar que, ainda hoje, mais da metade da população não se 
encontra representada politicamente, o que infere daí sérias correlações de defesa de direitos que não são acolhidos, embora a dicotomia existente não seja amplamente reconhecida (BELLOZO, 2008, p.18).

Através do avanço do movimento feminista, as mulheres aos poucos começaram a ocupar lugar nos espaços políticos, onde atuavam na reivindicação dos direitos, o que melhor é traduzido por Arendt (1950).

A politica, assim aprendemos, é algo como uma necessidade imperiosa para a vida humana e, na verdade, tanto para a vida dos indivíduos como da sociedade. Como o homem não e autárquico, porém depende de outros em sua existência, precisa haver um provimento da vida relativo a todos, sem o qual não seria possível justamente o convívio (ARENDT, 1950, p. 11).

No Brasil, os avanços na participação política feminina são simbolizados e em 1932, através de um código eleitoral provisório permitindo a participação das mulheres no sufrágio, desde que obedecessem alguns requisitos impostos como a comprovação de certa quantia em dinheiro, no caso das solteiras e viúvas, as casadas só com autorização expressa pelo marido e as divorciadas era vetado o direito ao voto. Há apenas 73 anos, em 1946, o direito ao voto foi ampliado à todas, sem a exigência dos requisitos a cumprir estabelecidos em 1932, ano do código eleitoral provisório.

O ano de 1946 trouxe, portanto a amplitude do direito ao voto as mulheres, mas esta equiparação não se estendeu à sociedade, onde as diferenças nos

mais variados aspectos se mantiveram ou pouco diminuiu. Feitas algumas considerações em relação a mulher na política brasileira, analisa-se conceitualmente o processo de tomada de decisão.

\section{Tomada de decisão}

O processo propulsor de desenvolvimento, tanto regional quanto no âmbito do município, passa pelo processo de tomada de decisões. Como este trabalho ajusta o foco na arena política, mas especificamente na Câmara Municipal, onde os agentes políticos propõem através de projetos de lei, 
iniciativas relacionadas à ideia de desenvolvimento e como tais proposições passam pelo embate político e pela tomada de decisão, antes de se tornarem leis, revisita-se aqui o processo de decisão nas organizações. Inicialmente resgatando a visão de Ramos (1983) e na sequência, de outros teóricos que se alinham à visão guerreirista.

Tomar decisão nas organizações faz parte do cotidiano do processo, a tomada de decisão acontece o tempo todo, em todos os níveis e influencia diretamente o desempenho da organização. Sua importância é tão nítida, que pode ser percebida empiricamente ao se analisar as organizações.

A teoria comportamental da decisão possui abordagens que resultam do exame de como tomadores de decisão se comportam, uma vez que as pesquisas sobre decisão mostram em diversos campos, que as pessoas tendem a cometer os mesmos tipos de erros e a observação destes erros é necessária para no processo de tomada de decisão, as más escolhas sejam minimizadas, conforme Russo e Schoemaker (1983, p. 13).

A decisão nas organizações é tida como um processo circular e multidimensional, uma verdadeira constelação e galáxia de numerosas decisões individuais, implicando num continuo de modelos que variam da racionalidade clássica em um polo a uma extrema intuição, no outro, como bem esclarece Ramos (1983, p. 38).

No comportamento organizacional, o processo de decisão abarca fatos e valores que se apresentam de tal modo interligados que as decisões poucas vezes se verificam como a única ou melhor solução, mas ao contrário, resgata Ramos (1983), numa recorrência frequente e de sucessivas comparações limitadas.

O processo de decisão, a partir da teoria guerreirista, teria por base a concepção tridimensional da racionalidade administrativa, qual seja, adotando os modelos clássico, normativo e comportamental. O primeiro considera os fins e formula numa perspectiva mecanicista, os meios adequados para atingi-los, segundo uma equação que tende aos requisitos de ser a melhor e única (decisão). 
O segundo modelo, normativo, envolve uma supervalorização das regras técnicas e de normas ditas científicas e confina o administrador num mundo abstrato de preceitos e enunciados sobre o que deve ser e assim inabilitando-o para compreender que na prática, os fatos não são necessariamente flexíveis aos padrões do código profissional da organização.

Ramos (1983) traz ainda o modelo comportamental, no qual é considerado "plástico", entendendo como a ação do administrador quando procura minimizar as resistências que por força de valores, convicções e emoções possam encontrar as suas decisões. Este modelo postula, na visão de Ramos (1983) a possibilidade de efetivamente conciliar as expectativas dos agentes organizacionais com os fins das decisões, ou ainda encerra a ideia que o agente tem um sentimento de poder e é um bom político.

$\mathrm{Na}$ teoria guerreirista tem-se ainda que na prática as decisões estão referidas a pontos de informação localizados dentro e fora da organização como aponta Ramos (1983, p. 39). O processo de decisão dentro de uma organização, independentemente do modelo adotado, está diretamente relacionado à situação de poder, também analisada por Ramos (1983, p. 39), ao afirmar que política e poder que até bem pouco tempo pareciam categorias concernentes às relações sociais macroscópicas, são hoje vistas como categoria do comportamento administrativo.

Para este autor, a política e o poder deixaram de ser vistas como manifestações clandestinas nas organizações e ganharam um quadro formal nos estudos organizacionais, tendo em vista o foco no resultado buscado pela organização.

E mesmo com o objetivo traçado pelos atores no encadeamento do processo decisório, nem todo resultado positivo é garantido uma vez que todo o esforço que seja um elemento de organização ou todo esforço coordenativo coordenado compreende dois atos de decisão; o primeiro é a decisão da pessoa afetada, sobre se contribuirá ou não com este esforço, como assunto de escolha pessoal.

Para Ramos (1983) é um detalhe do processo de escolhas pessoais que determina se continuará ou não colaborando com o processo na organização e 
esta decisão está fora do sistema de esforços que a constituem, ainda que seja objeto do processo. Torna-se uma questão intrínseca que foge das estratégias organizacionais e do processo de decisão, como lembra este autor.

Na dialética de tomada de decisão, Druker (2002, p. 111) afirma que as pessoas eficazes não tomam decisão e sim, procuram verificar o que é estratégico e amplo, em vez de resolver problemas.

Para Druker (2002) as pessoas eficazes sabem quando uma decisão deve se basear em princípios e quando esta deve ser tomada devido aos méritos do caso e da pragmaticidade.

Druker (2002) entende que o processo de decisão pode ser convertido em cinco passos que revelam seus aspectos, sendo: a percepção clara de que o problema era geral e que só poderia ser resolvido com uma decisão que estabelecesse uma regra, um princípio; a definição das especificações que a resposta ao problema tinha que externar; a definição do que é certo; a seleção, dentro de um processo de decisão, da ação a ser realizada e por último, o feedback que testa a validade e a eficácia da decisão em confronto com o curso real dos acontecimentos.

\section{Como as mulheres de Sant'ana do Livramento decidem}

Para se atingir o objetivo deste trabalho, de entender como se dá a tomada de decisão das mulheres integrantes do espaço politico em Sant'Ana do Livramento, foram ouvidas as duas vereadores titulares de mandato e a atual vice-prefeita municipal. Todas as três foram receptivas à pesquisa e manifestaram curiosidade quanto ao tema em questão.

Com relação ao perfil das entrevistadas, duas delas, uma vereadora e a vice-prefeita tem formação superior em Direito. A primeira exerce advocacia e a segunda atualmente não. A terceira entrevistada é estudante de ensino superior de Direito, aluna do terceiro semestre em universidade local e donade-casa. Com relação às idades, as entrevistadas possuem 67, 54 e 49 anos respectivamente e esta ultima é de etnia negra, enquanto as duas primeiras são de etnia branca. Elas serão chamadas aqui de E1, E2 e E3, respectivamente entrevistadas um dois e três. 
Todas as três responderam ao roteiro de perguntas elaboradas para a entrevista e teceram largamente considerações sobre o assunto da tomada de decisão e quanto aos resultados toma-se por norte que a tomada de decisão em ambiente eminentemente político tem variáveis que devem ser consideradas, entrando em jogo no processo não apenas uma estratégia planejada, mas participam do processo outros elementos. Três mulheres diferentes, que representam diferentes segmentos da sociedade fronteiriça são responsáveis pelas decisões que impactam diretamente no conjunto da sociedade, e entre eles apenas duas mulheres vereadoras, o que significa que as decisões têm o viés de gênero pouco representativo numericamente, considerando que são atualmente dezessete vereadores em exercício de mandato parlamentar.

E como foi dito por Ramos (1983) no comportamento organizacional, o processo de decisão abarca fatos e valores que se apresentam de tal modo interligados que as decisões poucas vezes se verificam como a única ou melhor solução, numa recorrência frequente e de sucessivas comparações limitadas.

Esta percepção pode ser verificada através da fala das mulheres deste artigo, quando questionados sobre como se dá o processo de decisão ao proporem projetos e ao voto, as vereadoras dizem tomar decisão a partir do que consideram ser o melhor para coletividade, com algumas variações de resposta como a de E3 que menciona "devido a demanda do povo". A entrevistada E1 alega tomar decisão a partir do que a consciência determina;

[..] então há uma estratégia que nós chamamos de estratégia politica e portanto, tanto o partido como a bancada acaba não votando por questões de estratégia politica e outa por questões de prioridade, porque se vê que tem um projeto que vá prejudicar principalmente a gente vê a questão daquele povo que é mais carente, que precisa dos mandatos, que precisa do poder publico, a gente acaba votando contra aquele projeto (E11).

Com relação ao questionamento quanto à existência de estratégia específica no processo de tomada de decisão, tendo à vista a arena política, os respondentes se posicionaram das mais diversas opiniões, o E3 afirma que existe sim estratégia na tomada de decisão. 
[...] olha, eu entendo que sim, porque eu vejo assim, sou uma neófita nesta área, que vejo que sim, no momento eu creio.. ainda voto com o coração, pensando não somente no poder político ou no meu partido, mas também nas pessoas (E3).

Esta visão é compartilhada pela entrevistada E2, ao dizer que:

"Eu acho que essa base que o governo tem hoje, ela foi uma base negociada, dificilmente esta base vai contrariar os interesses do executivo, todos têm cargo no governo, todos têm cargo"(E2).

$\mathrm{Na}$ busca de um melhor entendimento sobre os fatores que venham afetar o processo de tomada de decisão na Câmara de Vereadores, foi questionado as entrevistadas se as divergências de opiniões entre eles, posicionamentos heterogêneos e interesses diferentes afetavam as decisões.

Por meio da verbalização de cada uma neste quesito, foi possível entender que as entrevistadas alegam sofrer influência pelas divergências e interesses opostos quanto à tomada de decisão, no que se pode verificar no posicionamento de E2:

Afeta, ontem eu saí cansada pela semana toda, a divergência afeta sim, muito mal, a divergência quando ela é mal-intencionada ela me afeta, mas quando ela é política, faz parte do jogo, tu está aqui para isso. Quando tu coloca teu nome tu tá aqui para isso, tu é pedra e vitrine, mas tem certos tipos de posicionamento que a deslealdade te atinge muito, agora tem outros que não, como o vereador .... mesmo, que estava tendo um atrito bem constrangedor e eu na calçada, já esclareci e pedi que ele entendesse a minha posição porque ele era oposição e eu era líder de governo, então e que eu não atacava pessoas, atacava ideias e defendia ideias, mas tem umas que não tem como, tem umas que afetam, até por falta de ética, de caráter. ( E11).

Questionadas se as posições partidárias teriam influência na gestão de governo, as respostas em sua maioria, confirmaram a ideia de Sartori (1962) sobre a partidocracia ou seja, que a sede do poder se desloca do governo para os partidos, tamanha é a influencia que estes exercem nas 
administrações, o que poder ser visto em E1, E2 e E3 ao dizerem respectivamente que:

Sempre, infelizmente é o que nos causa tamanho problema, são as posições e a influência partidária, que nem sempre não é técnica é o que a gente vê, mas de acordo com o que o partido decide, é a briga de poder, infelizmente é $\operatorname{assim}(\mathrm{E} 3)$.

Sim, inclusive tem uma experiência pessoal onde eu queria votar num determinado vereador para Presidente da Casa e o partido fez uma ata, com fechamento de decisão, fechamento de diretório, fechamento determinando que os vereadores deveriam votar em x. Hoje o cargo é do partido, então tu tens autonomia, mas a tua autonomia tem os limites partidários (E1).

Ah eu não tenho dúvida disso, porque cada partido tem um ideário, um manifesto tem um programa. O PSB ao qual eu pertenço tem um programa partidário, e os outros têm os deles. Alguns partidos fazem desse ideário, destas bandeiras de luta apenas palavras escritas no papel, o PSB não, o nosso partido certamente enquanto governo ele tem uma diretriz, a partir daquilo que o partido pensa, portanto nós estamos sempre dando prioridade pra assistência social, sempre dá prioridade para a educação, para a saúde, sem deixar de olhar as outras demandas da sociedade, como infraestrutura, enfim como desenvolvimento econômico que é fundamental e básico, pra qualquer gestão e mas com foco no atendimento prioritário a população, então a visão de um partido orienta a sua ação enquanto governo (E2).

As falas das entrevistadas acima ferem a ideia do famoso pacto social teorizado por Rousseau (2014) ao defender que é importante que a vontade geral prevaleça, não podendo haver no Estado uma vontade parcial. Portanto, o ideário prevê que os interesses da coletividade se sobreponham aos interesses político, mas os vereadores admitem através das suas falas que o interesse partidário exerce sua influência sobre a administração pública local.

Foi perguntado as entrevistadas, como ultimo questionamento da pesquisa, se nas suas respectivas percepções, as manifestações populares, sejam elas pessoais ou digitais, afetam o embate politico na Câmara de 
Vereadores e as mulheres trouxeram para o discurso diversas colocações sobre o tema, com suas percepções sobre as manifestações democráticas.

A Câmara de Vereadores tem em seu Regimento Interno um dispositivo que prevê a realização de audiências públicas para ouvir a comunidade e discutir temas de interesse local e específico, quando alguma matéria ou projeto esteja por ser votado ou venha causando polêmica no município.

Este legislativo também possui outras ferramentas para interação com a comunidade, como um serviço de ouvidoria em seu site institucional, página em Facebook na qual são registradas diariamente, diversas manifestações populares acerca dos mais variados temas e interação simultânea com as sessões, transmitidas on line.

A página possui atualmente mais de cinco mil curtidas, e no link de recomendações e avaliações, tem registros de críticas por "não ouvir o povo", possui ainda em sua timeline, inúmeras manifestações sobre assuntos que são publicados diariamente, como a agenda dos vereadores, por exemplo. Com relação a participação popular, manifestações sejam elas pessoais ou digitais, todas três afirmaram ser este um processo legítimo, democrático e que deve ser respeitado pelos indivíduos que estão em exercício do mandato, embora digam que as manifestações não chegam a atingir a tomada de decisão no ambiente político. A vice-prefeita no entanto disse que o povo ainda não tem consciência da força que possui, pois se organizado através dos movimentos sociais e do ativismo torna-se sim, capaz de mudar o rumo das decisões por parte tanto do legislativo quanto do executivo.

Analisando estas ponderações, percebe-se uma flexibilização das opiniões, as mulheres manifestando valorização do sistema democrático, onde a opinião de todos deve ser considerada, o que nos reporta ao seguinte pensamento: A democracia se configura num sistema de governo imprevisível, por abrir múltiplas possibilidades na esfera do poder, coexistindo visões e perspectivas divergentes (ROUSSEAU, 2014).

O debate democrático deve ser marcado pela transparência, clareza de propostas, coerência ética e comprometimento social e o aprimoramento da 
democracia acontece na medida em que as escolhas individuais passam a acontecer a partir da compreensão do bem comum, ideia tão bem defendida por Rousseau (2014).

As mulheres receptivas as manifestações trouxeram para suas falas posicionamentos como de E2, ao dizer que:

“..Com certeza, com certeza, quanto mais as pessoas se mobilizarem para manifestar sua opinião, s e a população não percebe que seus anseios estão atendidos, ela tem que se posicionar, tem que reivindicar, eu acho que hoje, atualmente os políticos não perceberam ainda a força da rede social, estamos vivendo um novo momento da sociedade e a rede social possibilitou uma forma muito mais democrática embora ali também tu tenha que saber ter filtro e tenha que saber separar o que é bom, a crítica vazia, da desconstrução pessoal ou política..” (E2).

\section{Considerações finais}

A democracia é um sistema de governo em que todas as importantes decisões políticas estão com o povo, ou seja, exige a participação da sociedade no processo decisório. As participações se dão em vários âmbitos e no caso, buscou-se verificar como as mulheres em exercício de mandato, parlamentar e executivo, reagem no processo de tomada de decisão, considerando elas são numericamente maioria na sociedade, no entanto sua representatividade politica ainda é tímida em Sant'Ana do Livramento, realidade essa que se reproduz em vários municípios pelo Brasil.

A partir dos questionamentos e das manifestações das entrevistadas, pode-se entender que as mulheres no cenário politico de Sant'Ana do Livramento tomam decisão pelo que consideram ser o melhor para a coletividade, embora admitam que sofrem influência das determinações de seus partidos. Elas percebem e acompanham as manifestações e interações da sociedade, que se dá de forma pessoal, com contato direto com estas mulheres ou por meio digital, este último fortemente.

Pela observação participante, pode-se perceber que as vereadoras não utilizam atividades de aproximação com a comunidade, como reuniões em associações de moradores ou outros espaços coletivos. Já a vice-prefeita, pela 
observação, procura estar nos espaços coletivos e ter contato mais direto com a população local.

Quanto à pouca representatividade feminina nos espaços de decisão, as entrevistadas manifestaram não refletir muito sobre o assunto, focando-se mais no que chamam de segmento de eleitorado como um todo, não vendo a representatividade como recorte de gênero. Tal constatação torna-se um contraditório frente a crescente estatística de poucas políticas públicas para mulheres, principalmente as em situações de violência e por desigualdades no mercado de trabalho.

Portanto, torna-se imprescindível que mais mulheres ocupem os espaços públicos, numa pluralidade democrática, ampliando as possibilidades de políticas públicas para mulheres, garantindo o "lugar de fala" e ampliando o debate sobre igualdade de direitos.

\section{Referências}

BRASIL, Tribunal Superior Eleitoral. Disponível em: < http://www.tse.jus.br/imprensa/noticias-tse/2019/Marco/numero-demulheres-eleitas-em-2018-cresce-52-6-em-relacao-a-2014 > Acesso em: 12 jan. 2019.

, Instituto Brasileiro de Geografia e Estatistica. Disponível em: <https://cidades.ibge.gov.br/>. Acesso em: 18.mar. 2019.

BELLOZO, Edson. A Mulher na Política Brasileira: Um Estudo da SubRepresentação Feminina. Tese do curso de Mestrado. Universidade de Londrina. 2006. Disponível em: < http://www.snh2013.anpuh.org/resources/anpuhpr/anais/ixencontro/comunic acao-individual/EdsonBelozzo.htm > Acesso em 16.03.2019.

DRUCKER. Peter Ferdinand. O melhor de Peter Drucker. São Paulo: Nobel, 2002.

RAMOS, Antônio Guerreiro. A Dinâmica da Sociedade Política no Brasil. Belo Horizonte: Revista Brasileira de Estudos Políticos, 1961.

ROUSSEAU, Jean-Jacques. Do Contrato Social. São Paulo: Hunterboks, 2014.

RUSSO, J. Edward. SCHOEMAKER, Paul J. H. Tomada de decisão: Armadilhas. Rio de Janeiro: Saraiva, 1993. 
SARTORI, Giovanni. Teoria Democrática. Brasília: Fundo de Cultura Brasil/Portugal, 1962.

Recebido em junho de 2019. Aprovado em dezembro de 2019. 